Federal Reserve Bank of Minneapolis

Research Department Staff Report 191

May 1995

\title{
An Equilibrium Model of the Business Cycle With Household Production and Fiscal Policy
}

\author{
Ellen McGrattan* \\ Federal Reserve Bank of Minneapolis \\ Richard Rogerson* \\ University of Minnesota and Federal Reserve Bank of Minneapolis \\ Randall Wright* \\ University of Pennsylvania and Federal Reserve Bank of Minneapolis
}

\begin{abstract}
We estimate a dynamic general equilibrium model of the U.S. economy that includes an explicit household production sector and stochastic fiscal variables. We use our estimates to investigate two issues. First, we analyze how well the model accounts for aggregate fluctuations. We find that household production has a significant impact and reject a nested specification in which changes in the home production technology do not matter for market variables. Second, we study the effects of some simple fiscal policy experiments and show that the model generates different predictions for the effects of tax changes than similar models without home production.
\end{abstract}

\footnotetext{
*We thank seminar participants at Cornell, Georgetown, North Carolina State, Northwestern, Pennsylvania, Queens, Virginia, and the Federal Reserve Banks of Atlanta and Minneapolis for input. Frank Diebold and Victor Rios-Rull also provided very useful comments. The National Science Foundation provided financial support. The views expressed herein are those of the authors and not necessarily those of the Federal Reserve Bank of Minneapolis or the Federal Reserve System.
} 


\section{Introduction}

In this paper, we construct a dynamic general equilibrium model that integrates several formulations in the recent literature, and obtain maximum likelihood estimates of the parameter values using aggregate time series. We then use the model to study business cycles and to analyze the effects of fiscal policy changes. Key features of the specification are that it includes household production, government spending, and distortionary taxation. While all of these features have been shown to be important in isolation, there is good reason to expect that there may be interesting interactions between home production and the fiscal variables. This is the first attempt to analyze, and certainly the first attempt to estimate, a model that combines these features.

In terms of related literature, Benhabib, Rogerson, and Wright (1991) and Greenwood and Hercowitz (1991) show that real business cycle models with explicit household production sectors perform better than the standard real business cycle model (e.g., the base model in Hansen 1985) along several dimensions. Christiano and Eichenbaum (1992) show that introducing government spending also improves the ability of the base model to match certain key observations. Braun (1994) and McGrattan (1994) show how distortionary taxation affects the basic real business cycle model. We think it is important to include taxation and household production in the same model for the following reason. The extent to which either shocks to or permanent changes in fiscal variables matter depends on the extent of individuals' opportunities and willingness to substitute in and out of market (taxed) activities. Explicit modeling of a household or nonmarket sector is an attempt to provide details concerning the nature of this substitution.

Moreover, although previous work has shown that adding home production can improve the performance of business cycle models, the extent of the improvement depends critically on several parameters, including the elasticities of substitution between household and market variables in utility and production functions, as well as the stochastic properties of the household and market technologies. As emphasized by Kydland (1995), there is little independent information regarding these parameters, and when existing studies calibrate their models they are forced to set some crucial parameters 
more or less arbitrarily (although recently Rupert, Rogerson, and Wright 1995 have attempted to measure some of the elasticity parameters using micro data; see below). This is what leads us to estimate the model. ${ }^{1}$ When we do so, we find that the overall fit is very good and that the estimates are robust to different ways of detrending the data. Also, our specification nests a model without home production that is very similar to the one in McGrattan (1994), and we find that the nested model is rejected.

We then ask of our estimated model the same question that economists who calibrate business cycle models typically ask: how well does it account for a set of statistics that are meant to capture the basic business cycle facts? It is by no means a foregone conclusion that our estimated model will do well along this dimension, since the estimation procedure is designed to fit the time series at all frequencies and not just business cycle frequencies. It turns out that the estimated model performs well, capturing most of the standard business cycle statistics at least as well as other models in the literature, and capturing some of them better. Based on these findings, we would argue that a model with home production should be the benchmark by which other models in this class are compared.

We then use the model to predict the effects of tax changes. We consider several policy experiments to illustrate how our model differs from standard models, including eliminating the capital income tax, eliminating distortionary taxation entirely, and changing the tax treatment of residential capital. We compute changes in steady state levels of consumption, output, capital, labor hours, and welfare that result from these policy changes. It turns out that, for our estimated parameter values, the model predicts that these experiments have very different effects from those predicted by similar models without home production.

The inclusion of home production affects the response of individuals to tax changes to the extent that they are willing to substitute between market and nonmarket activity. Similarly, the business cycle implications of either technology or fiscal policy shocks depend on this same willingness. The

\footnotetext{
${ }^{1}$ Previous attempts to estimate similar models using maximum likelihood methods include Christiano (1988), Altug (1989), McGrattan (1994), and Leeper and Sims (1994); but none of these studies use models that include household production.
} 
reason for the above results - that the model accounts for the business cycle better than a model without home production and that it predicts different tax effects than a model without home production - is that our estimates imply individuals have a fairly high elasticity of substitution between market and household consumption goods.

The rest of the paper is organized as follows. In Section 2 we present the model and define equilibrium. In Section 3 we describe the estimation procedure and data. In Section 4 we discuss the empirical results. In Section 5 we focus on business cycle implications, and in Section 6 we analyze the fiscal policy experiments. Section 7 contains some brief summary remarks.

\section{The Model}

The framework is a discrete-time stochastic growth model with a $[0,1]$ continuum of identical infinitely-lived individuals. Preferences of individuals are defined over stochastic processes for consumption $c_{t}$ and leisure $\ell_{t}$, as described by the utility function

$$
E_{0} \sum_{t=0}^{\infty} \tilde{\beta}^{t} u\left(c_{t}, \ell_{t}\right)
$$

where $E_{0}$ is the expectation operator conditional on information available at date 0 and $\tilde{\beta}$ is the discount factor. Momentary utility is assumed to be a constant relative risk aversion transformation of a Cobb-Douglas function,

$$
u\left(c_{t}, \ell_{t}\right)=\frac{\left(c_{t}^{b} \ell_{t}^{1-b}\right)^{1-\sigma}-1}{1-\sigma} .
$$

Leisure is given by

$$
\ell_{t}=\bar{h}-h_{m t}-h_{n t},
$$

where $\bar{h}$ is total discretionary time, $h_{m t}$ is hours of market work, and $h_{n t}$ is hours of nonmarket work (home work). Consumption is an aggregate of private consumption $c_{p t}$ and government consumption $c_{g t}$ :

$$
c_{t}=\left\{a_{1} c_{p t}^{b_{1}}+\left(1-a_{1}\right) c_{g t}^{b_{1}}\right\}^{1 / b_{1}} .
$$

Private consumption itself is an aggregate of market consumption $c_{m t}$ and nonmarket consumption $c_{n t}$ :

$$
c_{p t}=\left\{a_{2} c_{m t}^{b_{2}}+\left(1-a_{2}\right) c_{n t}^{b_{2}}\right\}^{1 / b_{2}} .
$$


For notational convenience, we combine (2)-(5) to write the momentary utility function as

$$
u\left(c_{t}, \ell_{t}\right)=U\left(c_{m t}, c_{n t}, c_{g t}, h_{m t}, h_{n t}\right) .
$$

The household maximizes utility subject to several constraints. First, it owns capital $k_{t}$ that it can divide at a point in time between market capital $k_{m t}$ and nonmarket capital $k_{n t}$,

$$
k_{t}=k_{m t}+k_{n t} .
$$

The household combines nonmarket capital with hours to produce the nonmarket good according to the home production function

$$
c_{n t}=g\left(k_{n t}, \mu^{t} e^{s_{n t}} h_{n t}\right)=\left\{a_{3} k_{n t}^{b_{3}}+\left(1-a_{3}\right)\left(\mu^{t} e^{s_{n t}} h_{n t}\right)^{b_{3}}\right\}^{1 / b_{3}},
$$

where $\mu$ is a trend growth rate and $s_{n t}$ is a stochastic shock, both of which are labor augmenting. Constraint (8) says that home consumption must be produced in the home (that is, $c_{n t}$ must be consumed by the household, and cannot be bought or sold on the market).

The household's capital stock evolves according to the law of motion

$$
k_{t+1}=(1-\tilde{\delta}) k_{t}+i_{t},
$$

where $i_{t}$ denotes investment and $\tilde{\delta}$ is the depreciation rate. Capital that is not used in home production is rented to firms in the market. The market variables are constrained according to a standard budget equation

$$
c_{m t}+i_{t}=\left(1-\tau_{h t}\right) w_{t} h_{m t}+\left(1-\tau_{k t}\right) r_{t} k_{m t}+\tilde{\delta} \tau_{k t} k_{m t}+T_{t},
$$

where $w_{t}$ and $r_{t}$ are the real wage rate and rental rate on capital, $\tau_{h t}$ and $\tau_{k t}$ are (stochastic) taxes on labor and capital income, and $T_{t}$ is a lump-sum transfer. Note that depreciation of market capital is tax deductible, which is why $\tilde{\delta} \tau_{k t} k_{m t}$ appears on the right-hand side, and that the household has no dividend income since profits will be zero in equilibrium. Also note that we can always decompose $i_{t}$ into market plus nonmarket investment, $i_{t}=$ $i_{m t}+i_{n t}$, where $i_{j t}=k_{j t+1}-k_{j t}(1-\tilde{\delta})$ for each sector $j .^{2}$

\footnotetext{
${ }^{2}$ This decomposition is simply an accounting identity; in one period, the household chooses investment in total capital, and next period it allocates total capital to either market or nonmarket uses. Although we allow capital to move freely across sectors, it is rare that much capital is actually moved in equilibrium, since households typically want to add to both stocks to at least keep pace with depreciation and growth.
} 
Taxes in the model are determined by a fiscal authority that faces the budget constraint

$$
c_{g t}=H_{m t} w_{t} \tau_{h t}+K_{m t} r_{t} \tau_{k t}-\tilde{\delta} K_{m t} \tau_{k t}-T_{t},
$$

where the upper case variables $H_{m t}$ and $K_{m t}$ denote aggregate (or, equivalently, per capita) values of the corresponding lower case variables. We assume that government consumption is a stochastic process given by

$$
c_{g t}=\alpha_{t} Y_{t},
$$

where $\alpha_{t}$ is a random variable and $Y_{t}$ is aggregate market output. We treat the transfer $T_{t}$ as a residual that takes on whatever value that is necessary to satisfy the government budget constraint at each point in time, given $\alpha_{t}, \tau_{h t}$, and $\tau_{k t}{ }^{3}$ Notice that there is no tax on nonmarket capital. In the United States, residential capital is subject to a property tax, but this tax as well as interest payments on home mortgages are deductible against income taxes. We assume here that the net effect is approximately zero, although taxes on home capital are considered explicitly in Section 6.

Next we describe the technology in the market sector. All firms are assumed to have a constant returns to scale production function. With constant returns, the number of firms is not determinate, and so we normalize this number to unity. The production function is given by

$$
Y_{t}=f\left(K_{m t}, \mu^{t} e^{s_{m t}} H_{m t}\right)=\left\{a_{4} K_{m t}^{b_{4}}+\left(1-a_{4}\right)\left(\mu^{t} e^{s_{m t}} H_{m t}\right)^{b_{4}}\right\}^{1 / b_{4}},
$$

where $\mu$ is the trend growth rate (which is the same as in the household production function) and $s_{m t}$ is a technology shock. At each date, the firm hires labor and capital in the market (taking $w_{t}$ and $r_{t}$ as given) to maximize instantaneous profit,

$$
\Pi_{t}=Y_{t}-w_{t} H_{m t}-r_{t} K_{m t}
$$

Note that $\Pi_{t}=0$ in equilibrium, because of constant returns.

The final aspect of the environment to consider is the stochastic structure. At this point we present a general specification that will be restricted

\footnotetext{
${ }^{3}$ We assume that the government balances the budget each period. Although unrealistic, this greatly simplifies the analysis.
} 
later. The vector of exogenous stochastic variables at $t$ is given by $s_{t}=$ $\left(\alpha_{t}, s_{m t}, s_{n t}, \tau_{k t}, \tau_{h t}\right)$. We assume

$$
\gamma(L) s_{t+1}=\gamma_{0}+\gamma_{\epsilon} \epsilon_{t}
$$

where $L$ denotes the lag operator, $\gamma(L)=I-\gamma_{1} L \ldots-\gamma_{q} L^{q}$, and $\epsilon_{t}$ is a vector with $E \epsilon_{t}=0$ and $E \epsilon_{t} \epsilon_{t}^{\prime}=I$. Let $S_{t}=\left(s_{t}, s_{t-1}, \ldots, s_{t-q}\right)$. Then $S_{t}$ contains all of the information that is both available and relevant for forecasting future values of $s_{t}$. We write the law of motion for $S_{t}$ as $S_{t+1}=S\left(S_{t}, \epsilon_{t}\right)$.

If we were to define and analyze equilibrium for this economy directly, it would entail paths for capital, output, consumption, and investment in each sector that fluctuate around a trend with growth rate $\mu$ while leisure and hours worked in each sector fluctuate around a constant level. It is important for our computational and econometric methods to work with series that are stationary. Hence, we transform the economy by replacing $\mu$ with 1 in (8) and (13), replacing the discount factor $\tilde{\beta}$ with $\beta=\tilde{\beta} \mu^{b(1-\sigma)}$, and replacing the law of motion for capital in (9) with $k_{t+1}=(1-\delta) k_{t}+i_{t} / \mu$ where $\delta=1-(1-\tilde{\delta}) / \mu$. In what follows, we treat the transformed economy as the fundamental unit of analysis, since it generates stationary outcomes. The behavior of capital, output, consumption, and investment in the original model can be obtained from the same series for the transformed economy simply by adding geometric growth at rate $\mu$.

We now describe a recursive competitive equilibrium for the transformed economy. There are two aggregate state variables, $K_{t}$ and $S_{t}$, and one individual state variable, $k_{t}$. The individual household chooses a decision vector $d_{t}=\left(h_{m t}, h_{n t}, k_{m t}, k_{n t}, i_{t}\right)$, taking as given the aggregate decision vector as a function of the aggregate state, $D_{t}=D\left(K_{t}, S_{t}\right)$, where $D_{t}=$ $\left(H_{m t}, H_{n t}, K_{m t}, K_{n t}, I_{t}\right)$. The individual also takes as given the laws of motion $S_{t+1}=S\left(S_{t}, \epsilon_{t}\right), K_{t+1}=K_{t}(1-\delta)+I_{t} / \mu$, and $k_{t+1}=k_{t}(1-\delta)+i_{t} / \mu$, and the initial condition $\left(k_{0}, K_{0}, S_{0}\right)$. Finally, it takes as given the market wage, rental rate, government consumption, and lump sum transfer as functions of the aggregate state: $w_{t}=w\left(K_{t}, S_{t}\right), r_{t}=r\left(K_{t}, S_{t}\right), c_{g t}=c_{g}\left(K_{t}, S_{t}\right)$, and $T_{t}=T\left(K_{t}, S_{t}\right)$. Then the household's problem is a well-posed dynamic 
program. Bellman's equation is

$$
V\left(k_{t}, K_{t}, S_{t}\right)=\max _{d_{t}}\left\{U\left(c_{m t}, c_{n t}, c_{g t}, h_{m t}, h_{n t}\right)+\beta E_{t} V\left(k_{t+1}, K_{t+1}, S_{t+1}\right)\right\},
$$

where the maximization is subject to the capital constraint (7), the home production constraint (8), and the budget constraint (10).

The solution to the maximization problem in (16) yields a stationary decision rule for the household, $d_{t}=d\left(k_{t}, K_{t}, S_{t}\right)$. This determines an aggregate decision rule, $D_{t}=D\left(K_{t}, S_{t}\right)$, which in equilibrium must be consistent with what the individual takes as given. Also, we can use the necessary and sufficient conditions for the firm's problem,

$$
\begin{aligned}
r_{t} & =f_{k}\left(K_{m t}, H_{m t} e^{s_{m t}}\right), \\
w_{t} & =f_{h}\left(K_{m t}, H_{m t} e^{s_{m t}}\right),
\end{aligned}
$$

to determine wage and rental rates as functions of $\left(K_{t}, S_{t}\right)$, which must be consistent with what the individual takes as given. Finally, we can use

$$
\begin{aligned}
c_{g t} & =\alpha_{t} Y_{t}, \\
T_{t} & =H_{m t} w_{t} \tau_{h t}+K_{m t} r_{t} \tau_{k t}-\tilde{\delta} K_{m t} \tau_{k t}-c_{g t},
\end{aligned}
$$

to determine fiscal policy as functions of $\left(K_{t}, S_{t}\right)$, which must be consistent with what the individual takes as given.

These considerations lead us to formally define an equilibrium for our economy as follows:

Definition: A recursive competitive equilibrium is given by a household value function $V(k, K, S)$ and decision rule $d(k, K, S)$, an aggregate decision rule $D(K, S)$, wage and rental rate functions $w=w(K, S)$ and $r=r(K, S)$, and policy functions $c_{g}(K, S)$ and $T(K, S)$, satisfying:

(a) the dynamic programming problem (16);

(b) the profit maximization conditions (17) and (18);

(c) the fiscal policy equations (19) and (20);

(d) the consistency requirement $D(K, S)=d(K, K, S)$. 


\section{$3 \quad$ Estimation Procedure and Data}

We use a procedure motivated by Sargent (1989), and described in detail in Hansen, McGrattan, and Sargent (1994), to solve and estimate the model. The reader is referred to those papers for details, and we provide only a brief overview here.

First, we use a deterministic version of the model, in which $\epsilon_{t} \equiv 0$, to find the nonstochastic steady state. Then we substitute the individual household's home production function and budget constraint into its objective function, and replace wages, rental rates, and fiscal variables using conditions (17)-(20), in order to write the household's objective function as a function of $\left(k, K, S, d, K_{m}, H_{m}\right) .{ }^{4}$ Following Kydland and Prescott (1982), we then approximate this function using a second order Taylor series around the nonstochastic steady state values of the arguments. This yields a linearquadratic version of the dynamic programming problem in (16), which generates linear Euler equations and linear decision rules. To find equilibria, we have to equate individual and aggregate variables in the Euler equations and solve for time paths of the variables of interest. ${ }^{5}$

This procedure generates the mapping

$$
x_{t+1}=A_{o} x_{t}+C w_{t+1}
$$

where $x_{t}=\left(k_{t}, S_{t}\right), E w_{t}=0$, and $E w_{t} w_{t}^{\prime}=I$ for all $t$. From (21) and the decision rules we can derive the paths for all of the endogenous variables. The elements of $A_{o}$ are nonlinear functions of the preference and technology parameter vector

$$
\Gamma=\left(\beta, b, \sigma, a_{1}, b_{1}, a_{2}, b_{2}, a_{3}, b_{3}, a_{4}, b_{4}, \delta, \mu\right)
$$

as well as the parameters in the law of motion (15). The elements of $C$ are linear functions of the elements of $\gamma_{\epsilon}$. We allow variables to be measured

\footnotetext{
${ }^{4}$ Note that we replace wage, rental rate, and fiscal policy variables with functions of aggregate (not individual) values of $K_{m}$ and $H_{m}$.

${ }^{5}$ Because equilibria in our model do not solve a social planning problem, we cannot guarantee ex ante either existence or uniqueness. However, our estimated parameter values satisfy the relevant stability conditions for the existence of a unique equilibrium.
} 
with error. ${ }^{6}$ This yields a measurement equation

$$
z_{t}=G x_{t}+v_{t}
$$

where $z_{t}=\left[k_{t}, h_{m t}, i_{t}, c_{g t}, y_{t}, k_{n t}, \tau_{k t}, \tau_{h t}\right]$ is a vector of observables and $v_{t}$ is a vector of measurement errors. We assume that

$$
v_{t}=D v_{t-1}+\eta_{t}
$$

where $E \eta_{t}=0$ and $E \eta_{t} \eta_{t}^{\prime}=R$.

As in Hansen, McGrattan, and Sargent (1994), we specify our empirical model in state space form:

$$
\begin{aligned}
x_{t+1} & =A_{o} x_{t}+C \omega_{t+1} \\
\bar{z}_{t} & =\bar{G} x_{t}+G C \omega_{t+1}+\eta_{t+1} .
\end{aligned}
$$

System (25) is obtained by differencing (23) so that $\bar{z}_{t}=z_{t+1}-D z_{t}$, and $\bar{G}=G A_{o}-D G$. If the disturbances, $\omega_{t}$ and $\eta_{t}$, are normal, then estimation involves maximizing the log-likelihood function (ignoring the constant term)

$$
L(\Theta)=-\frac{1}{2} T \ln |\Omega|-\frac{1}{2} \sum_{t=1}^{T} u_{t}^{\prime} \Omega^{-1} u_{t},
$$

where $u_{t}=z_{t+1}-\hat{E}\left[z_{t+1} \mid z_{t}, z_{t-1}, \ldots, z_{0}, \hat{x}_{0}\right]$ is the innovation in $z_{t+1}, \Omega=$ $E u_{t} u_{t}^{\prime}, \hat{x}_{0}$ is an initial condition for $x$ (assumed here to be the steady state of the vector of state variables), and $\Theta$ includes $\Gamma$ plus the parameters of the processes in (15) and (24). Hansen, McGrattan, and Sargent (1994) show how to construct the sequence of innovations by applying a Kalman filter to system (25). They also provide derivatives of the log-likelihood function.

Issues that arose during the course of estimation lead us to place some additional restrictions on parameters. The first concerns the magnitude of measurement errors. Since there are many different estimates for effective marginal tax rates, we anticipated that our tax series were likely to be measured with the greatest error. Initial estimation, however, suggested that the tax rates were measured very precisely whereas quantities (e.g., hours, investment, and capital) were measured with a lot of error.

\footnotetext{
${ }^{6}$ Given the large differences in marginal tax rates across studies, the possibility of measurement error seems particularly important for the tax series.
} 
In order to allow our priors about measurement error to influence the estimation procedure, we impose that the variance of the measurement error for all quantities is at most 5 percent of the total variance of each series. At least for the case of market hours, the data provides some guidance for this magnitude, since there are two series gathered for market hours (the Household and the Establishment series). Assuming that these two series are each equal to the true hours plus measurement error that is independent across the two series, the covariance of the two series provides an measure of the true variance and hence an estimate of measurement error variance. The five percent figure is based on this calculation. In contrast, we do not impose any bounds on the magnitude of measurement error in the tax series. While this procedure is obviously somewhat informal, it is a simple way to let the estimation procedure make use of the fact that the marginal tax rate series are very noisy.

A second issue concerns the fact that there are some near unit roots in the data for certain variables. We deal with this in two ways. First, we put restrictions on the eigenvalues of the system of exogenous states in (15) and on the eigenvalues of the matrix governing serial correlation in the measurement errors. The eigenvalues of $\gamma$ were restricted to be less than 0.998 in absolute value. For the matrix $D$ we restricted its eigenvalues to be less than 0.8. If we allowed the eigenvalues of $D$ to be close to 1 , then we would essentially be first-differencing the data and putting very little weight on sample means. The second way in which we address the unit root problem is to estimate the model using filtered data. Using filtered data greatly reduces the unit-root problem, and additionally provides a check on the robustness of our key parameter estimates.

A final issue concerns the specification of the shock to the home production function. We have estimated the model imposing several different restrictions. The results reported in the next section are for the case in which the home technology shock is assumed to be uncorrelated with all other shocks. We have also studied two other cases: one in which the process for the home shock is allowed to be correlated with all other shocks, and one in which there are assumed to be no shocks to the home technology. As we describe below, our major conclusions are not affected by the choice of 
specification for the home technology shock. ${ }^{7}$

We now turn to a description of the data. All series are quarterly, for the period 1947-1992, and are in real per capita terms. The series for investment, government consumption, private market consumption, and market output are taken from the National Income and Product Accounts. Investment is defined as fixed investment plus purchases of consumer durables. Private market consumption is defined as the consumption of nondurables and services, excluding the service flow attributed to the housing stock (since we interpret the latter component as nonmarket rather than market consumption). Government consumption is defined to be government purchases of goods and services less purchases of nonmilitary durables and structures. Market output is defined as the sum of investment, government consumption, and private market consumption (hence, it excludes net exports).

Market capital is the net stock of private nonresidential structures and equipment. Nonmarket capital is the net stock of private residential capital and consumer durables. These series are obtained from the Survey of Current Business, and are annual data interpolated to quarterly data. The market hours series is defined as total manhours for all industries and all employees taken from the Bureau of Labor Statistics' Household Survey. This is seasonally adjusted monthly data aggregated to quarterly data. The total hours parameter $\bar{h}$ is set to 1,134 hours per quarter (a little over 12 hours per day), which is the measure of discretionary time we took from Hill (1985).

The tax rates on labor and capital income are constructed using the definitions in Joines (1981); they are annual data interpolated to quarterly data. The Appendix contains the actual series. Sources for these measures are the National Income and Product Accounts and the Statistics of Income series of

\footnotetext{
${ }^{7}$ It is important to emphasize that, even if the home technology is nonstochastic, introducing a home production sector into an otherwise standard model leads to very different propagation mechanisms for other shocks. Hence, home production models do not need shocks to the home production function in order to generate different predictions from models without home production. One result in Benhabib, Rogerson, and Wright (1991) does require a shock to the home sector: the ability of that particular home production model to account for the low correlation between hours worked and productivity found in the data. It is well known that to account for this fact a model needs to have more than one shock; but the model in this paper already has shocks to government spending and tax rates, so a stochastic home technology is not crucial in this regard.
} 
the Internal Revenue Service. The tax rate on labor corresponds to Joines' definition of MTRL1, and the tax rate on capital to Joines' definition of MTRK1 (excluding property tax revenue). We do not have data on nonmarket hours or nonmarket output. Nonetheless, it is still possible to draw inferences about the parameters of the preferences and technology for home production, because other observable variables depend on these parameters.

\section{Empirical Results}

In this section we describe the empirical results and discuss some of their implications. We begin with preference and technology parameters. Estimates and standard errors for these are found in Table $1 \mathrm{a} .^{8}$

The estimates for $a_{1}, b_{1}, \sigma, \tilde{\delta}, \tilde{\beta}$, and $\mu$ are similar to estimates for the model without home production found in McGrattan (1994), and so we discuss these only briefly. The parameter $a_{1}$, which measures the weight on private (versus public) consumption in the household utility function, hit an upper bound of 1 and was therefore constrained during estimation; this means that $b_{1}$ is not identified and can be set arbitrarily. When $a_{1}=1$, government consumption does not affect the marginal utility of private consumption, as has been simply assumed in some related models (e.g., Christiano and Eichenbaum 1992). The risk aversion parameter, $\sigma$, has a point estimate of 6.78 , but a large standard error; a log-linear specification for momentary utility is not inconsistent with the estimates. The estimate for depreciation, $\tilde{\delta}$, is 0.021 with a small standard error, which is consistent with results found elsewhere. The table reports an estimate for $\beta$ (from the transformed economy) of 0.985 ; the implied estimate of $\tilde{\beta}$ is 1.0018 . The estimate of the growth rate, $\mu$, is 1.0063 , with a small standard error; this is in the range of sample growth rates for our capital stock, output, and investment series.

As mentioned earlier, a key parameter governing the interaction between household and market activity is $b_{2}$, since the elasticity of substitution between the market and nonmarket consumption goods is $1 /\left(1-b_{2}\right)$. Thus,

\footnotetext{
${ }^{8}$ In what follows, tables and figures labeled "a" are derived from estimation of the model assuming geometric growth in the raw data; tables and figures labeled "b" are derived from estimation after filtering the data as described below.
} 
$b_{2}$ measures the willingness of agents to substitute between the two goods. For example, if $b_{2}$ is equal to 1 then $c_{m}$ and $c_{n}$ are perfect substitutes, and if $b_{2}$ is equal to 0 then $c_{p}$ is a Cobb-Douglas function of $c_{m}$ and $c_{n}$ so they are complements. Benhabib, Rogerson, and Wright (1991) show that, under certain assumptions, adding home production to their model has no effect on market variables when $b_{2}$ is equal to 0 . Our point estimate of $b_{2}$ is 0.429 , and it is significantly different from zero. It is also in the range of values found by Rupert, Rogerson, and Wright (1995) looking at microeconomic data on different demographic groups (single men, single women, and married couples). A value for $b_{2}$ of 0.429 implies a fairly high willingness to substitute between home and market goods, although less than assumed by Benhabib, Rogerson, and Wright (1991), who set $b_{2}$ to 0.8 in their preferred model.

We can conduct a formal test of the hypothesis that home production does not matter for market activity as follows. Consider a version of the model in which $b_{2}=0, b_{3}=0$, and $\sigma=1$ (that is, $c_{p}$ is a Cobb-Douglas function of $c_{m}$ and $c_{n}, c_{n}$ is a Cobb-Douglas function of $k_{n}$ and $h_{n} e^{s_{n}}$, and $u$ is a $\log$-linear function of $c$ and $\ell$ ). In this case, innovations in $s_{n t}$ do not affect any of the variables in equilibrium except $c_{n t} .{ }^{9}$ We test the hypothesis that these restrictions hold against the unconstrained alternative. The hypothesis is easily rejected using a likelihood ratio test: the probability that $\chi^{2}(3)$ falls below the computed likelihood ratio test statistic is essentially 1 . We conclude that changes in relative productivity between the home and market have a significant impact on market variables.

The remaining preference parameters in Table $1 \mathrm{a}$ are $a_{2}$ and $b$, which measure the weight on market (versus home) consumption and the weight on

\footnotetext{
${ }^{9}$ This can be verified as follows. First, we substitute the equilibrium conditions for $w$, $r$, etc. into the first order conditions from (16). We then seek restrictions under which $s_{n}$ does not affect $d=\left(h_{m}, h_{n}, k_{m}, k_{n}, i\right)$, but only affects $c_{n}$. If $b_{2}=0, s_{n}$ drops out of the equation for $h_{m}$ (because when $c_{p}$ is a Cobb-Douglas function of $c_{m}$ and $c_{n}, c_{n}$ does not affect the marginal rate of substitution between $c_{m}$ and $h_{m}$ ). If $b_{3}=0, s_{n}$ drops out of the equations for $h_{n}, k_{n}$, and $k_{m}$ (because when the home production function is CobbDouglas, the desired capital-labor ratios do not depend on $s_{n}$ ). If $\sigma=1, s_{n}$ drops out of the Euler equations for $i$ (because when the utility function is log-linear, $c_{n}$ does not affect the marginal utility of $c_{m}$ ), at least as long as $s_{n}$ does not matter for the expectation of the future values of $s_{m}$ or the fiscal variables, as we are assuming here. These are exactly the conditions described in the text.
} 
consumption (versus leisure) in momentary utility. These parameters have implications for the allocation of time between the home and market; in fact, previous studies have used microeconomic data on time use to draw inferences on $a_{2}$ and $b$. For example, based on cross-section data described in Juster and Stafford (1991), Greenwood, Rogerson, and Wright (1995) report that market work and home work constitute 33 and 25 percent of discretionary time for a typical U.S. household, and use this to calibrate $a_{2}$ and $b$. The mean of our market hours series is 27 percent of $\bar{h}$. We do not have data on home hours, but the model predicts $h_{n}$ is about 15 percent of $\bar{h}$ on average.

We next consider estimates of the production functions. First, note that $b_{4}$ is not significantly different from zero, so that a Cobb-Douglas market technology is consistent with the estimates. On the other hand, the estimate of $b_{3}$ is at least 1 standard deviation different from 0 , indicating that the home production function is not Cobb-Douglas. The weight on capital in the market technology, $a_{4}$, is 0.220 . This is similar to estimates found by others (Christiano and Eichenbaum 1992, for example) who ignore both household production and taxation. These two features tend to have offsetting effects on the estimated value of $a_{4}$. On the one hand, adding capital income taxation to a model causes the estimate of $a_{4}$ to rise, since capital has to be more productive in order to generate the observed stock when it is subject to taxation (McGrattan 1994, for example, estimates $a_{4}$ to be 0.4). On the other hand, incorporating home production causes the estimate of $a_{4}$ to fall, because a large fraction of observed capital is assumed to be allocated to home production. The net effect of these two considerations is an estimate close to that found by authors who neglect both taxation and household production.

We now turn to the stochastic process for the exogenous state variables, which was assumed to have two lags $(q=2)$ in the estimation exercise. Estimates and standard errors are reported in Figure 1a. The results indicate that the vector autoregressive process for the exogenous states is highly persistent. The estimation procedure attempts to capture low frequency movements in the data either through $\gamma(L)$ or through the measurement error process. Estimates of the measurement error process are shown in Figure 2a (note that the measurement errors on output and government consumption 
are assumed to be zero, and that only hours of work and the tax rates are assumed to have serially correlated measurement errors). Trends are particularly evident in the tax rate series, where $\tau_{h t}$ increases while $\tau_{k t}$ decreases over our sample. This causes a near unit root estimate in the labor tax rate process. There is also a trend in the series for $h_{m t}$. The result is that the eigenvalues of $D$ are at their upper bound.

Because of these considerations, we have also estimated the model using data that was first transformed using the Hodrick-Prescott (HP) filter (see Prescott 1986), thereby eliminating low frequencies. We tried this not only because of trends in the market hours and tax rate series, but also because the theoretical model implies that all series that grow must grow at the same geometric rate. Although this may be correct from some very long run perspective, the growth rates do not match perfectly in our relatively short sample. The filtered case provides a check on the robustness of our utility and production function parameter estimates, in the sense that we can see if they are sensitive to the low frequency properties of the data. Note that in this estimation exercise we do use information about sample means, i.e., the data are the filtered series added to their sample means.

Table $1 \mathrm{~b}$ and Figures $1 \mathrm{~b}$ and $2 \mathrm{~b}$ report the results for this case. Notice that the utility and production function parameters are very similar to those in Table 1a: the differences in point estimates are less than one standard deviation for all parameters except $\delta$. The main differences between the filtered and unfiltered cases are the estimates of the autoregressive process and the measurement error equations. In particular, after filtering low frequencies in the data we do not have difficulties with near unit roots, with the exception of the process for the home shock, which has an eigenvalue at the upper limit of $0.998 .^{10}$

Lastly, we make a few remarks concerning the role of household productivity shocks. The above results show that if we estimate a model with a stochastic home production sector, then it is found that home production "matters." Two natural questions arise. The first is how important quan-

\footnotetext{
${ }^{10} \mathrm{With}$ respect to measurement error variance, we note that in the unfiltered case, the five percent limits were binding for both investment and market hours, whereas in the filtered case the limit was binding for both capital and investment. For parameters at their bounds, we do not report standard errors.
} 
titatively are the home technology shocks, and the second is whether the basic finding that home production matters is sensitive to the presence of home technology shocks. Although we do not report the results here in any detail, note that home shocks are relatively insignificant, accounting for only a small fraction of fluctuations in output for any ordering of the elements of $\epsilon_{t}$. Regarding the second question, the result that home production matters does not depend critically on the presence of home technology shocks. The reason is simple: what matters in the model is relative productivity differentials across the two sectors, and even if the home sector is deterministic, as long as the market sector is stochastic there will be fluctuations in relative productivity.

Allowing home shocks to be correlated with other shocks also does not affect our main findings, although for details of this case the reader is referred to McGrattan, Rogerson, and Wright (1993). An additional piece of information that is generated with that specification is the correlation between home and market technology shocks, a parameter that Benhabib, Rogerson, and Wright (1991) emphasized in their analysis. Our estimate of this correlation was basically zero, and hence this specification does not differ a lot from the case discussed above, where the correlation was assumed to be zero.

\section{Cyclical Implications}

It is standard in the real business cycle literature to focus on a small set of summary statistics describing relative volatilities of a few series and their correlations with output. A common question that arises in that context is to what extent those particular features are being matched at the expense of others that are not being reported. The formal estimation procedure used in the last section obviously does not place all of the weight on this small set of summary statistics, and it is of interest to see what the resulting parameter estimates imply for these commonly studied statistics. Table 2a uses estimates obtained for the model with geometric growth estimated on the raw data, and Table $2 \mathrm{~b}$ uses the estimates obtained for the Hodrick - Prescott

filtered data. Both the model and data series are logged before computing the standard deviations, so these statistics are in percentage terms. The 
column headed 'Model Forecast' indicates that $G \hat{E}\left[x_{t} \mid \bar{z}_{t-1}, \bar{z}_{t-2}, \ldots, \bar{z}_{0}, \hat{x}_{0}\right]$ is used to obtain the model's predictions, where $\hat{x}_{0}$ is an estimate of the initial state. $^{11}$

Consider Table 2a, which compares the model and the data for the case of geometric growth. Overall, the match is quite good. There are two discrepancies worth noting. One is that the statistics related to the tax rates are off by a fair margin. This is perhaps not surprising since our assumptions lead to relatively large estimates for measurement error in these series. The other major discrepancy is the correlation between market hours and output. In the data this number is basically zero, whereas in the model it is 0.75 . The trend in market hours causes this correlation in the data. This trend in hours is absent from the model, and hence it cannot match this correlation. Note that the two investments are both positively correlated with output in the model, as they are in the data, a feature stressed by Greenwood and Hercowitz (1991).

Now consider Table 2b, which compares the model and data in the case where estimation uses Hodrick - Prescott filtered data. Again, the fit seems to be quite good, although in the model total investment is somewhat too smooth and, therefore, market consumption is somewhat too volatile. Overall, we would say that the model does at least as well as a typical real business cycle model in matching the set of second moments on which real business cycle theorists tend to concentrate.

\section{$6 \quad$ Fiscal Policy Experiments}

In this section we analyze the effects of three fiscal experiments: eliminating all tax distortions by setting both the labor and capital tax rates to zero; reducing the capital income tax rate to zero while increasing the labor income tax rate to keep revenue constant; and introducing a tax on nonmarket capital. We would not argue that these experiments are the only ones of interest; our point is simply to show how the predictions for a given policy experiment will differ in our model and a similar model without household

\footnotetext{
${ }^{11}$ Although the tables only report standard deviations and correlations with output, note that the first moments all match very well.
} 
production.

For the first two policy experiments, Table 3 reports percent changes in output, consumption, investment, hours worked, and capital in both the home and market sectors, plus a variable $\Delta$ that measures the welfare consequences in terms of market consumption. It is interpreted as follows: if, for example, $\Delta=1$, then agents would be equally well off after the policy change if their market consumption were reduced by 1 percent of its new steady state value, all else being the same. Percentage changes are relative to a base case with $\tau_{k}=0.55$ and $\tau_{h}=0.24$ (the sample averages in the data). The first experiment sets $\tau_{k}=\tau_{h}=0$, and the second sets $\tau_{k}=0$ and sets $\tau_{h}$ at the indicated level in order to keep revenue constant. Government consumption is the same in each case, and is set to balance the budget in the base case; in the experiment with $\tau_{k}=\tau_{h}=0, c_{g}$ is financed exclusively via lump sum taxation.

Based on our parameter estimates, the effect of eliminating distorting taxation altogether is quite sizable: output increases by 46 percent, market consumption increases by 55 percent, market investment increases by 82 percent, market hours increase by 25 percent, and the stock of market capital more than doubles. In the home sector, consumption decreases by 2.1 percent, hours decrease by 20 percent, and capital increases by 35 percent. Hence, there is a shift of labor from home to market production, but an increase in capital in both sectors. In terms of welfare, the policy change is worth 30 percent of market consumption. A model that ignores the home sector has very different predictions. For example, as shown in the second column of the table, the model in McGrattan (1994) predicts for the same policy change an increase in both output and market consumption of 55 percent and an increase in total capital of 124 percent, much larger than in our model. The response of market hours is roughly the same for the two models; but, because home hours change in our model, the implications for leisure are different. In terms of welfare, the policy is worth 27.1 percent of market consumption in the model without home production. ${ }^{12}$

\footnotetext{
${ }^{12}$ We emphasize that the above calculation is only illustrative in nature, meant to indicate that the same calculation in the two frameworks can lead to very different answers. Steady state comparisons measure how much one would be willing to pay to move to a country with a different policy, but not how much one would pay to change an existing
} 
Now consider the effect of eliminating the capital tax and raising the labor tax to keep revenue constant. Given our estimates, the labor tax rate would have to increase from 0.24 to 0.32 percent. This is accompanied by a 12 percent increase in output, a 7 percent increase in market consumption, a 41 percent increase in investment, an 85 percent increase in the market capital stock, and a 4 percent decrease in market hours. The welfare gain is 13.5 percent of market consumption. In contrast, the model without home production predicts that eliminating capital taxation requires increasing $\tau_{h}$ to 0.37 to keep revenue constant, that output increases by 19 percent, market consumption increases by 7 percent, investment and the capital stock both increase by 72 percent, and market hours fall by 6 percent. The welfare gain is 13.1 percent of consumption. Once again, there are big differences between the models with and without home production.

For the final experiment, we consider adding a tax on household capital (an experiment that cannot be conducted in a model without home production, of course). We replace the individual budget constraint with

$$
c_{m}+i=\left(1-\tau_{h}\right) w h_{m}+\left(1-\tau_{k}\right) r k_{m}+\tilde{\delta} \tau_{k} k_{m}+T-\tau_{p} k_{n}
$$

where $\tau_{p}$ is a "property" tax. Jorgenson and Yun (1991) argue that a value of $\tau_{p}=0.01$ is realistic when it is interpreted as a residential property tax. ${ }^{13}$ Table 4 reports percent changes for output, consumption, investment, hours worked, and capital in both the home and market sectors, plus our welfare measure for economies with $\tau_{p}=0.01,0.02$, and 0.03 relative to a base case with $\tau_{p}=0$. In all cases, we set $\tau_{h}=0.24$ and $\tau_{k}=0.55$.

With the exception of market consumption, all variables are lower when $\tau_{p}$ is positive than in the base case. Output produced at home falls 9 percent when $\tau_{p}$ is increased to 0.01 . At $\tau_{p}=0.03$, home production falls 22 percent. Not surprisingly, there is a significant decrease in home capital, which is the factor being taxed. Hours in home production fall but only slightly. Because

policy. Obviously, if one were enacting changes in tax laws starting from an intial steady state, the relevant welfare comparison needs to take into account the transition path. Our point here is merely to show in a simple setting that the answer to a given question is significantly altered by the presence of a home sector.

${ }^{13}$ Assuming an interest rate of 4 percent annually, a tax of 0.01 on the value of capital corresponds to a 25 percent tax rate on the flow of services. 
home capital is produced in the market, market production also falls when $\tau_{p}$ is increased. Notice that inputs and outputs in the market fall by the same percentages. This follows from the fact that the property tax does not affect the market capital/labor ratio. The tax leads to a large fall in investment, and households increase their market consumption. The subsidy to market consumption needed to leave households indifferent between having $\tau_{p}>0$ and $\tau_{p}=0$ is given in the last row of Table 4 . For $\tau_{p}=0.01$, the subsidy required is 4.3 percent of market consumption. At $\tau_{p}=0.03$, the subsidy required is 11.5 percent.

To summarize, the model can be used to analyze a wide variety of fiscal policy issues. Some, like the effects of a change in the tax treatment of housing, can only be analyzed seriously in a model with an explicit household sector. Others, like the effects of changes in capital taxation, can be analyzed in models without home production, but the predictions change once the household sector is incorporated.

\section{Conclusion}

In this paper, we evaluate the importance of home production in models of aggregate economic activity by obtaining maximum likelihood estimates of a stochastic growth model with an explicit household sector. The parameter that is most important for the hypothesis that household production affects market activity is the elasticity of substitution between output of the two sectors. Our estimates suggest that there is a significant elasticity of substitution between home and market goods. Furthermore, we can reject restrictions on the model that imply market activity is not affected by changes in relative productivity across the two sectors. We also examine how well the estimated model accounts for the standard set of moments on which real business cycle theorists focus, and use the model to study the effects of fiscal policy changes. We find that including home production significantly affects the model's predictions for these issues. There are a variety of other issues for which the addition of an explicit home production sector may make a difference. In such cases, the model and the parameter estimates in this paper may prove useful. 


\section{Appendix}

The effective tax rates for labor and capital used to estimate the model are given in Table A. The data sources for these series are Statistics of Income, Individual Income Tax Returns (Sources of Income and Taxable Income, all returns) and Social Security Bulletin (Tables 2a, 4b). The rates are constructed using the definitions of Joines (1981), series MTRK1, MTRL1. One important difference between $\tau_{k, t}$ of Table A and MTRK1 in Joines is the treatment of property taxes. MTRK1 is the sum of a proportional tax on income that is not specific to capital or labor, a proportional tax on income that is specific to capital, and a nonproportional tax on income that is specific to capital. The proportional tax on income that is specific to capital is simply tax receipts from capital divided by income from capital. We exclude property taxes from both tax receipts and Joines' measure of income which includes indirect business taxes.

\begin{tabular}{ccc|ccc|ccc}
\hline$t$ & $\tau_{k t}$ & $\tau_{h t}$ & $t$ & $\tau_{k t}$ & $\tau_{h t}$ & $t$ & $\tau_{k t}$ & $\tau_{h t}$ \\
\hline 1947 & 62.0 & 20.0 & 1963 & 56.2 & 22.6 & 1979 & 53.4 & 27.3 \\
1948 & 54.3 & 17.2 & 1964 & 54.2 & 21.4 & 1980 & 54.3 & 29.0 \\
1949 & 51.7 & 17.2 & 1965 & 52.2 & 20.6 & 1981 & 51.5 & 29.5 \\
1950 & 63.1 & 18.3 & 1966 & 52.3 & 21.4 & 1982 & 49.3 & 28.9 \\
1951 & 66.2 & 19.8 & 1967 & 53.0 & 21.7 & 1983 & 46.9 & 28.2 \\
1952 & 62.9 & 20.9 & 1968 & 58.4 & 23.3 & 1984 & 45.2 & 27.5 \\
1953 & 63.7 & 21.0 & 1969 & 59.7 & 24.4 & 1985 & 46.2 & 27.4 \\
1954 & 59.8 & 19.5 & 1970 & 54.4 & 24.9 & 1986 & 51.7 & 27.2 \\
1955 & 58.7 & 19.6 & 1971 & 56.4 & 23.6 & 1987 & 50.5 & 26.9 \\
1956 & 60.4 & 20.2 & 1972 & 56.8 & 24.0 & 1988 & 49.4 & 26.1 \\
1957 & 59.5 & 21.0 & 1973 & 56.8 & 24.6 & 1989 & 48.6 & 25.8 \\
1958 & 59.2 & 20.8 & 1974 & 59.4 & 25.9 & 1990 & 47.3 & 26.0 \\
1959 & 59.4 & 21.4 & 1975 & 54.6 & 25.8 & 1991 & 46.7 & 26.2 \\
1960 & 59.6 & 21.7 & 1976 & 56.7 & 25.8 & 1992 & 48.2 & 26.0 \\
1961 & 59.9 & 22.0 & 1977 & 54.4 & 26.6 & & & \\
1962 & 56.1 & 22.2 & 1978 & 53.3 & 26.5 & & & \\
\hline
\end{tabular}

Table A. Effective Tax Rates for Capital and Labor 


\section{References}

Altug, Sumru (1989), "Time-to-Build and Aggregate Fluctuations: Some New Evidence," International Economic Review, 30: 889-920.

Benhabib, Jess, Richard Rogerson, and Randall Wright (1991), "Homework in Macroeconomics: Household Production and Aggregate Fluctuations," Journal of Political Economy, 99: 1166-1187.

Braun, R. Anton (1994), "Tax disturbances and Real Economic Activity in the Postwar United States," Journal of Monetary Economics, 33: $441-462$.

Christiano, Lawrence J. (1988), "Why Does Inventory Investment Fluctuate So Much?" Journal of Monetary Economics, 21: 247-280.

Christiano, Lawrence J. and Martin Eichenbaum (1992), "Current Real Business Cycle Theories and Aggregate Labor Market Fluctuations," American Economic Review, 82: 430-450.

Greenwood, Jeremy and Zvi Hercowitz (1991), "The Allocation of Capital and Time over the Business Cycle," Journal of Political Economy, 99: $1188-1214$.

Greenwood, Jeremy, Richard Rogerson, and Randall Wright (1995), "Household Production in Real Business Cycle Theory," in Frontiers of Business Cycle Research, ed. T.F. Cooley, Princeton: Princeton University Press.

Hansen, Gary D. (1985), "Individual Labor and the Business Cycle," Journal of Monetary Economics, 16: 309-327.

Hansen, Lars P., Ellen R. McGrattan, and Thomas J. Sargent (1994), "Mechanics of Forming and Estimating Dynamic Linear Economies," Research Department Staff Report 182, Federal Reserve Bank of Minneapolis.

Hill, M. (1985), "Patterns of Time Use," in Time, Goods and Well-Being, eds. F.T. Juster and F.P. Stafford, Ann Arbour: University of Michigan Press. 
Joines, Douglas H. (1981), "Estimates of Effective Marginal Tax Rates on Factor Incomes," Journal of Business, 54: 191-226.

Jorgenson, Dale W. and Kun-Young Yun (1991), Tax Reform and the Cost of Capital, Oxford: Clarendon Press.

Juster, F. Thomas and Frank P. Stafford (1991), "The Allocation of Time: Empirical Findings, Behavioral Models, and Problems of Measurement," Journal of Economic Literature, 29: 471-522.

Kydland, Finn E. (1995), "Business Cycles and Aggregate Labor Market Fluctuations," in Frontiers of Business Cycle Research, ed. T.F. Cooley, Princeton: Princeton University Press.

Kydland, Finn E. and Edward C. Prescott (1982), "Time to Build and Aggregate Fluctuations," Econometrica, 50: 1345-1370.

Leeper, Eric and Christopher Sims (1994), "Toward a Modern Macroeconomic Model Usable for Policy Analysis," NBER Macroeconomics Annual 1994, eds. S. Fischer and J. Rotemberg, Cambridge: MIT Press.

McGrattan, Ellen R. (1994), "The Macroeconomic Effects of Distortionary Taxation," Journal of Monetary Economics, 33: 573-601.

McGrattan, Ellen R., Richard Rogerson, and Randall Wright (1993), "Household Production and Taxation in the Stochastic Growth Model," Research Department Staff Report 166, Federal Reserve Bank of Minneapolis.

Prescott, Edward C. (1986), "Theory Ahead of Business Cycle Measurement," Carnegie-Rochester Conference on Public Policy, 25: 11-44.

Rupert, Peter, Richard Rogerson, and Randall Wright (1995), "Estimating Substitution Elasticities in Household Production Models," Economic Theory, in press.

Sargent, Thomas J. (1989), "Two Models of Measurements and the Investment Accelerator," Journal of Political Economy 97: 251-287. 


\begin{tabular}{lll}
\hline Function & \multicolumn{2}{c}{ Parameter Estimates } \\
\hline$u(c, l)=\frac{\left(c^{b} l^{1-b}\right)^{1-\sigma}}{1-\sigma}$ & $b=\underset{(0.233)}{0.466}$ & $\sigma=\underset{(5.985)}{6.783}$ \\
$c=\left\{a_{1} c_{p}^{b_{1}}+\left(1-a_{1}\right) c_{g}^{b_{1}}\right\}^{1 / b_{1}}$ & $a_{1}=\underset{1.0}{1.0}$ & $b_{1}=0$ \\
$c_{p}=\left\{a_{2} c_{m}^{b_{2}}+\left(1-a_{2}\right) c_{n}^{b_{2}}\right\}^{1 / b_{2}}$ & $a_{2}=\underset{(0.250)}{0.414}$ & $b_{2}=\underset{(0.116)}{0.429}$ \\
$c_{n}=\left\{a_{3} k_{n}^{b_{3}}+\left(1-a_{3}\right)\left(e^{s_{n}} h_{n}\right)^{b_{3}}\right\}^{1 / b_{3}}$ & $a_{3}=\underset{(0.166)}{0.206}$ & $b_{3}=\underset{(0.123)}{0.189}$ \\
$y=\left\{a_{4} k_{m}^{b_{4}}+\left(1-a_{4}\right)\left(e^{s_{m}} h_{m}\right)^{b_{4}}\right\}^{1 / b_{4}}$ & $a_{4}=\underset{(0.173)}{0.220}$ & $b_{4}=\underset{(0.270)}{0.053}$ \\
$k^{\prime}=(1-\tilde{\delta}) k / \mu+i / \mu$ & $\tilde{\delta}=\underset{(0.00003)}{0.0214}$ & $\mu=\underset{(0.0001)}{1.0063}$ \\
$\beta$ & $\beta=\underset{(0.017)}{0.985}$ & \\
\hline
\end{tabular}

Table 1a. Parameters of Preferences and Technology (Geometric detrending)

\begin{tabular}{lll}
\hline Function & \multicolumn{1}{c}{ Parameter Estimates } \\
\hline$u(c, l)=\frac{\left(c^{b^{1} l^{1-b}}\right)^{1-\sigma}}{1-\sigma}$ & $b=\underset{(0.173)}{0.489}$ & $\sigma=\underset{(4.037)}{5.799}$ \\
$c=\left\{a_{1} c_{p}^{b_{1}}+\left(1-a_{1}\right) c_{g}^{b_{1}}\right\}^{1 / b_{1}}$ & $a_{1}=1.0$ & $b_{1}=0$ \\
$c_{p}=\left\{a_{2} c_{m}^{b_{2}}+\left(1-a_{2}\right) c_{n}^{b_{2}}\right\}^{1 / b_{2}}$ & $a_{2}=\underset{(0.185)}{0.412}$ & $b_{2}=\underset{(0.082)}{0.326}$ \\
$c_{n}=\left\{a_{3} k_{n}^{b_{3}}+\left(1-a_{3}\right)\left(e^{s_{n}} h_{n}\right)^{b_{3}}\right\}^{1 / b_{3}}$ & $a_{3}=\underset{(0.114)}{0.140}$ & $b_{3}=\underset{(0.066)}{0.269}$ \\
$y=\left\{a_{4} k_{m}^{b_{4}}+\left(1-a_{4}\right)\left(e^{s_{m}} h_{m}\right)^{b_{4}}\right\}^{1 / b_{4}}$ & $a_{4}=\underset{(0.041)}{0.206}$ & $b_{4}=\underset{(0.083)}{0.054}$ \\
$k^{\prime}=(1-\tilde{\delta}) k / \mu+i / \mu$ & $\tilde{\delta}=\underset{(0.00003)}{0.0295}$ & $\mu=1.0$ \\
$\beta$ & $\beta=\underset{(0.004)}{0.987}$ & \\
\hline
\end{tabular}

Table 1b. Parameters of Preferences and Technology (HP detrending) 


$$
\begin{aligned}
& s_{t+1}=\left(\begin{array}{llll}
\alpha & s_{m} & s_{n} & t_{k}
\end{array} t_{h}\right)_{t+1}^{\prime}=\left(\begin{array}{ccccc}
-.00343 & .103 & 0 & .0395 & .0174 \\
\underset{(.0593)}{(.0954)} & & .0441) & (.04)
\end{array}\right) \\
& +\left(\begin{array}{ccccc}
1.51 & .0166 & 0 & -.0807 & .446 \\
(.262) & (.32) & & (.603) & (.355) \\
.372 & .893 & 0 & .14 & -.0787 \\
(.522) & (.0445) & & (.64) & (.546) \\
0 & 0 & .627 & 0 & 0 \\
& & (.201) & & \\
.0185 & -.0592 & 0 & 1.67 & .122 \\
(.203) & (.208) & & (.33) & (.206) \\
-.0735 & -.0241 & 0 & .0445 & 1.33 \\
(.185) & (.164) & & (.309) & (.112)
\end{array}\right) s_{t} \\
& +\left(\begin{array}{ccccc}
-.557 & -.00845 & 0 & .112 & -.515 \\
(.283) & (.342) & & (.612) & (.372) \\
-.198 & .0537 & 0 & -.158 & -.1 \\
(.493) & (.0706) & & (.672) & (.547) \\
0 & 0 & .0502 & 0 & 0 \\
& & (.146) & & \\
.00666 & .0372 & 0 & -.667 & -.155 \\
(.178) & (.211) & & (.333) & (.218) \\
.093 & .0181 & 0 & -.0369 & -.392 \\
(.175) & (.178) & & (.31) & (.124)
\end{array}\right) s_{t-1}
\end{aligned}
$$

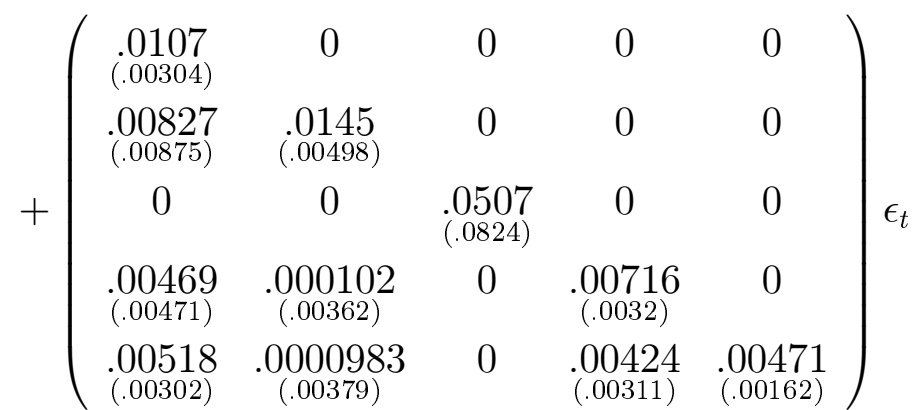

Figure 1a. Parameter estimates of the vector autoregressive process for exogenous state variables (Geometric detrending)

$$
\begin{aligned}
& D_{i i}=(0, .800,0,0,0,0, .800, .800) \\
& R_{i i}=\left(\begin{array}{cccccccc}
1380 & 2.09 & 195 & 0 & 0 & \underset{(105)}{39.7} & \underset{\left(5.92 \times 10^{-5}\right)}{2.16 \times 10^{-4}} & \underset{\left(9.55 \times 10^{-5}\right)}{2.23 \times 10^{-4}}
\end{array}\right)
\end{aligned}
$$

Figure 2a. Parameter estimates of the measurement error equations (Geometric detrending) 


$$
\begin{aligned}
& s_{t+1}=\left(\begin{array}{llll}
\alpha & s_{m} & s_{n} & t_{k}
\end{array} t_{h}\right)_{t+1}^{\prime}=\left(\begin{array}{ccccc}
-.00218 & .073 & 0 & .0453 & .0152 \\
(.0306) & (.0664) & & (.0516) & (.027)
\end{array}\right) \\
& +\left(\begin{array}{ccccc}
1.31 & .0145 & 0 & -.0784 & .267 \\
(.0947) & (.0322) & & (.0775) & (.294) \\
.332 & .945 & 0 & .13 & -.0792 \\
(.282) & (.0658) & & (.188) & (.461) \\
0 & 0 & .95 & 0 & 0 \\
.0184 & -.0517 & 0 & 1.38 & .125 \\
(.29) & (.0572) & & (.194) & (.507) \\
-.0777 & -.0211 & 0 & .0406 & 1.25 \\
(.127) & (.0303) & & (.0979) & (.171)
\end{array}\right) s_{t} \\
& +\left(\begin{array}{ccccc}
-.353 & -.0092 & 0 & .127 & -.422 \\
(.0796) & (.034) & & (.0832) & (.319) \\
-.182 & .0436 & 0 & -.21 & -.113 \\
(.26) & (.0612) & & (.185) & (.534) \\
0 & 0 & .0478 & 0 & 0 \\
.00665 & .0443 & 0 & -.447 & -.113 \\
(.244) & (.0565) & & (.186) & (.513) \\
.0739 & .0214 & 0 & -.0378 & -.342 \\
(.0973) & (.0301) & & (.0895) & (.176)
\end{array}\right) s_{t-1}
\end{aligned}
$$

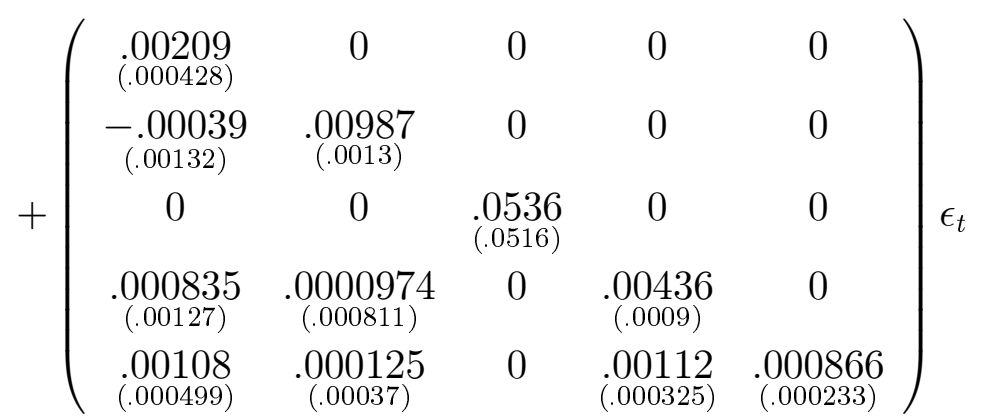

Figure 1b. Parameter estimates of the vector autoregressive process for exogenous state variables (HP detrending)

$$
\begin{aligned}
& D_{i i}=\left(\begin{array}{llllllll}
.638 & .401 & .673 & .0005 & .535 & .005 & .800 & .800 \\
& (.173) & & (1.32) & (.224) & (25.7) & (.0509) & (.0424)
\end{array}\right) \\
& R_{i i}=\left(\begin{array}{llllllll}
298 & \underset{(.353)}{923} & 29.5 & \underset{(19.6)}{1.02} & \underset{(3.80)}{11.5} & \underset{(16.3)}{0111} & \underset{\left(1.15 \times 10^{-5}\right)}{6.32 \times 10^{-5}} & \underset{\left(6.6 \times 10^{-7}\right)}{2.37 \times 10^{-6}}
\end{array}\right)
\end{aligned}
$$

Figure 2b. Parameter estimates of the measurement error equations (HP detrending) 


\begin{tabular}{lcccc}
\hline & \multicolumn{2}{c}{ Data } & \multicolumn{2}{c}{ Model Forecast } \\
Series $(z)$ & $\operatorname{std}(\ln (z))$ & $\operatorname{corr}(z, y)$ & $\operatorname{std}(\ln (z))$ & $\operatorname{corr}(z, y)$ \\
\hline Output & 14.27 & 1.00 & 14.17 & 1.00 \\
Market consumption & 12.99 & 0.97 & 12.76 & 0.98 \\
Total investment & 10.25 & 0.80 & 10.37 & 0.80 \\
Market investment & 18.59 & 0.78 & 22.42 & 0.67 \\
Home investment & 19.27 & 0.78 & 19.03 & 0.77 \\
Government consumption & 26.06 & 0.93 & 26.03 & 0.93 \\
Market hours & 3.54 & -0.01 & 3.17 & 0.75 \\
Total capital & 6.89 & 0.91 & 6.59 & 0.90 \\
Market capital & 6.61 & 0.91 & 6.08 & 0.86 \\
Home capital & 7.38 & 0.89 & 7.30 & 0.88 \\
Capital tax rate & 9.21 & 0.85 & 12.66 & 0.90 \\
Labor tax rate & 14.07 & -0.85 & 17.69 & 0.69 \\
\hline
\end{tabular}

Table 2a. Standard Deviations and Correlations for Data and Model (Geometric detrending)

\begin{tabular}{lcccc}
\hline & \multicolumn{2}{c}{ Data } & \multicolumn{2}{c}{ Model Forecast } \\
Series $(z)$ & $\operatorname{std}(\ln (z))$ & $\operatorname{corr}(z, y)$ & $\operatorname{std}(\ln (z))$ & $\operatorname{corr}(z, y)$ \\
\hline Output & 1.87 & 1.00 & 1.88 & 1.00 \\
Market consumption & 1.26 & 0.90 & 1.56 & 0.91 \\
Total investment & 5.08 & 0.69 & 4.63 & 0.66 \\
Market investment & 5.35 & 0.45 & 7.73 & 0.72 \\
Home investment & 5.84 & 0.03 & 5.84 & 0.03 \\
Government consumption & 4.46 & 0.46 & 4.34 & 0.40 \\
Market hours & 1.49 & 0.69 & 1.40 & 0.70 \\
Total capital & 0.45 & 0.67 & 0.49 & 0.57 \\
Market capital & 0.48 & 0.44 & 0.71 & 0.23 \\
Home capital & 0.56 & 0.67 & 0.56 & 0.68 \\
Capital tax rate & 3.13 & 0.23 & 1.95 & 0.67 \\
Labor tax rate & 2.48 & 0.26 & 1.98 & 0.69 \\
\hline
\end{tabular}

Table 2b. Standard Deviations and Correlations for Data and Model (HP detrending) 


\begin{tabular}{|c|c|c|c|c|}
\hline \multirow[b]{4}{*}{ Series } & \multicolumn{2}{|c|}{ (a) Lump-Sum Tax } & \multicolumn{2}{|c|}{ (b) No Capital Tax } \\
\hline & with & without & with & without \\
\hline & Household & Household & Household & Household \\
\hline & Sector & Sector & Sector & Sector \\
\hline Output & 45.7 & 55.3 & 12.1 & 19.4 \\
\hline Market consumption & 54.5 & 54.8 & 6.6 & 7.3 \\
\hline Total Investment & 82.2 & 123.5 & 41.0 & 71.9 \\
\hline Market capital & 140.3 & 123.5 & 85.0 & 71.9 \\
\hline Market hours & 24.6 & 22.2 & -4.1 & -6.0 \\
\hline Home consumption & -2.1 & 0.0 & 2.3 & 0.0 \\
\hline Home capital & 34.9 & 0.0 & 5.3 & 0.0 \\
\hline Home hours & -19.5 & 0.0 & 0.7 & 0.0 \\
\hline$\Delta$ & 30.1 & 27.1 & 13.5 & 13.1 \\
\hline
\end{tabular}

Table 3. Percent changes between case (a) $\tau_{k}=0, \tau_{h}=0$, or case (b) $\tau_{k}=0, \tau_{h}=0.32$ (with household production), and $\tau_{h}=0.37$ (without household production) and the base case $\left(\tau_{k}=0.55, \tau_{h}=0.24\right.$ )

\begin{tabular}{lccc}
\hline & \multicolumn{3}{c}{ Tax on Residential Capital } \\
Series & .01 & .02 & .03 \\
\hline Output & -1.04 & -1.49 & -1.64 \\
Market consumption & 3.47 & 6.13 & 8.26 \\
Total investment & -13.34 & -21.94 & -27.86 \\
Market capital & -1.04 & -1.49 & -1.64 \\
Market hours & -1.04 & -1.49 & -1.64 \\
Home consumption & -9.44 & -16.52 & -22.08 \\
Home capital & -23.33 & -38.54 & -49.14 \\
Home hours & -0.53 & -1.16 & -1.79 \\
$\Delta$ & 4.30 & 8.12 & 11.49 \\
\hline
\end{tabular}

Table 4. Percent changes between cases with

$$
\tau_{p}>0 \text { and base case }\left(\tau_{p}=0\right)
$$

